\title{
Expression of genes associated with BMP signaling pathway in porcine oocytes before and after IVM - a microarray approach
}

Joanna Budna', Marta Rybska², Sylwia Ciesiółka', Artur Bryja ${ }^{3}$, Sylwia Borys ${ }^{3}$, Wiesława Kranc ${ }^{3}$, Katarzyna Wojtanowicz-Markiewicz ${ }^{1,2}$, Michal Jeseta ${ }^{4}$, Ewa Sumelka ${ }^{1}$, Dorota Bukowska², Paweł Antosik2, Klaus P. Brüssow ${ }^{3}$, Małgorzata Bruska ${ }^{3}$, Michał Nowicki ${ }^{1}$, Maciej Zabel ${ }^{1}$ and Bartosz Kempisty ${ }^{1,3^{*}}$

\begin{abstract}
Background: The full maturational capability of mammalian oocytes is accompanied by nuclear and cytoplasmic modifications, which are associated with proliferation and differentiation of surrounding cumulus cells. These events are regulated on molecular level by the expression of target genes involved in signal transduction pathways crucial for folliculogenesis and oogenesis. Transforming growth factor beta signaling includes several molecules that are involved in the regulation of oogenesis and embryo growth, including bone morphogenetic protein (BMP). However, the BMP-related gene expression profile in oocytes at different maturational stages requires further investigation.

Methods: Oocytes were isolated from pubertal crossbred Landrace gilts follicles, selected with a use of BCB staining test and analyzed before and after in vitro maturation. Gene expression profiles were examined using an Affymetrix microarray approach and validated by RT-qPCR. Database for Annotation, Visualization, and Integrated Discovery (DAVID) software was used for the extraction of the genes belonging to a BMP-signaling pathway ontology group.

Results: The assay revealed 12,258 different transcripts in porcine oocytes, among which 379 genes were down-regulated and 40 were up-regulated. The DAVID database indicated a "BMP signaling pathway" ontology group, which was significantly regulated in both groups of oocytes. We discovered five up-regulated genes in oocytes before versus after in vitro maturation (IVM): chordin-like 1 (CHRDL1), follistatin (FST), transforming growth factor-beta receptor-type III (TGFßR3), decapentaplegic homolog 4 (SMAD4), and inhibitor of DNA binding 1 (ID1).

Conclusions: Increased expression of CHRDL1, FST, TGF $\beta R 3$, SMAD4, and ID1 transcripts before IVM suggested a subordinate role of the BMP signaling pathway in porcine oocyte maturational competence. Conversely, it is postulated that these genes are involved in early stages of folliculogenesis and oogenesis regulation in pigs, since in oocytes before IVM increased expression was observed.
\end{abstract}

Keywords: Pig, Oocytes, Microarray, In vitro maturation

\footnotetext{
* Correspondence: bkempisty@ump.edu.pl

'Department of Histology and Embryology, Poznan University of Medical

Sciences, Swiecickiego 6 St., 60-781 Poznan, Poland

${ }^{3}$ Department of Anatomy, Poznan University of Medical Sciences, Swiecickiego

6 St, 60-781 Poznan, Poland

Full list of author information is available at the end of the article
} 


\section{Background}

The mammalian cumulus-oocyte complexes (COCs) undergo growth, as well as substantial morphological and biochemical differentiation, during the long stages of folliculogenesis and oogenesis [1]. The biochemical changes include nuclear and cytoplasmic maturation of the oocyte and formation of gap junction connections (GJCs) between the gamete and surrounding somatic cells, which are associated with the bi-directional transport of small substances [2, 3]. The morphological changes involve follicle modifications that occur during their differentiation from primordial and preantral to the antral stage shortly before ovulation. Moreover, during COCs maturation the cumulus cells (CCs), which tightly surround the oocytes, significantly change their structure from compact in immature gametes to expanded, a marker of complete maturation [4]. It is suggested that during in vivo and in vitro mammalian COCs maturation their transcriptomic profile changes. Therefore, some differentially expressed genes may be recognized as new markers of maturational competence [5].

Recently, it was demonstrated that bone morphogenetic proteins (BMPs), apart from its role in bone formation, are involved in porcine folliculogenesis, early embryogenesis and morphogenesis in mammals [6]. Moreover, the BMP family of proteins regulates COCs maturation and achievement of the MII stage [7].

Transforming growth factors beta (TGF $\beta$ ) are a family of critical proteins that regulate somatic cell proliferation and differentiation both in vivo and in vitro. It has been recognized that the TGF superfamily members regulate important stages of folliculogenesis, oogenesis, and embryogenesis in mammals [8]. Additionally, TGF $\beta$ is an upstream activator of SMAD signaling pathway via BMPs kinases complexes [9]. Activation of TGF $\beta$ induces subsequent phosphorylation of SMAD2 and SMAD3, finally forming a complex with SMAD4 [10]. The latter, located in the nucleus, regulates expression of inhibitor of DNA binding 1 (ID1) during development and cells differentiation $[11,12]$. The ID1 protein contains helix-loop-helix (HLH) architecture and functions in several cell lineages as a regulator of gene transcription following binding to target transcription factors via HLH motif [13]. As the result can regulate growth and differentiation in embryonic tissues [14].

Follistatin (FST) is a negative regulator of follicle growth and function, since it inhibits follicle-stimulating hormone (FSH) release. Interestingly, its increased expression was found in human chondrocytes [15], where chordin-like 1 (CHRDL1) can be also found [16]. Furthermore, both are known as competitive inhibitors of BMPs [17].

Described signaling pathway governs follicle development in the ovary, as well as development and oocyte maturation and competency $[18,19]$, therefore our aim was to present the influence of BMP signaling pathway on maturation capability of porcine oocytes before and after IVM.

\section{Methods \\ Experimental design}

Collected oocytes were exposed to two Brilliant Cresyl Blue $(\mathrm{BCB})$ tests and divided into two groups. The first group (before IVM) included oocytes graded as BCBpositive $\left(\mathrm{BCB}^{+}\right)$and not subjected to further IVM. The second group (after IVM) included $\mathrm{BCB}^{+}$oocytes which were then in vitro matured, and graded as $\mathrm{BCB}^{+}$after IVM.

\section{Animals}

A total of 45 pubertal crossbred Landrace gilts bred on a commercial local farm were used in this study. They had a mean age of 155 days (range 140-170 days) and a mean weight of $100 \mathrm{~kg}(95-120 \mathrm{~kg})$. All animals were housed under identical conditions and fed the same forage (depending on age and reproductive status). All experiments were approved by the Local Ethic Committee.

\section{Collection of porcine ovaries and cumulus-oocyte-complexes (COCs)}

The ovaries and reproductive tracts were recovered at slaughter and transported to the laboratory within 40 min. at $38{ }^{\circ} \mathrm{C}$ in $0.9 \% \mathrm{NaCl}$. To provide optimal conditions for subsequent oocyte maturation and fertilization in vitro, the ovaries of each animal were placed in a $5 \%$ fetal bovine serum solution (FBS; SigmaAldrich Co., St. Louis, MO, USA) in PBS. Single large follicles $(>5 \mathrm{~mm})$ were opened by puncturing with a $5 \mathrm{ml}$ syringe and 20-G needle in a sterile Petri dish, and COCs were recovered. The COCs were washed three times in modified PBS supplemented with $36 \mu \mathrm{g} / \mathrm{ml}$ pyruvate, $50 \mu \mathrm{g} / \mathrm{ml}$ gentamycine, and $0.5 \mathrm{mg} / \mathrm{ml} \mathrm{BSA}$ (Sigma-Aldrich, St. Louis, MO, USA). COCs were selected under an inverted microscope Zeiss, Axiovert 35 (Lübeck, Germany), counted, and morphologically evaluated using the scale suggested by Jackowska et al. Only COCs of grade I possessing homogeneous ooplasm and uniform, compact cumulus cells were considered for further use, resulting in a total of 300 grade I oocytes $(3 \mathrm{x}$ $n=50$ before IVM group, $3 \times n=50$ after IVM group).

Assessment of oocyte developmental competence by $B C B$ test Brilliant Cresyl Blue (BCB) test, which measures activity of glucose-6-phosphate (G6PDH) enzyme, was used for assessment of oocytes' quality and maturity [20]. The G6PDH enzyme converts BCB stain from blue to colorless. In oocytes that completed the growth activity of the enzyme decreases and the stain cannot be reduced, 
resulting in blue oocytes $\left(\mathrm{BCB}^{+}\right)$. To perform the $\mathrm{BCB}$ staining test, oocytes were washed twice in modified Dulbecco's Phosphate Buffered Saline (DPBS) commercially supplemented with $0.9 \mathrm{mM}$ calcium, $0.49 \mathrm{mM}$ magnesium, $0.33 \mathrm{mM}$ pyruvate, and $5.5 \mathrm{mM}$ glucose (Sigma-Aldrich, St. Louis, MO, USA), and additionally with $50 \mathrm{IU} / \mathrm{ml}$ penicillin, $50 \mu \mathrm{g} / \mathrm{ml}$ streptomycin (SigmaAldrich, St. Louis, MO, USA), and 0.4\% Bovine Serum Albumin (BSA) $[w / v]$ (Sigma-Aldrich, St. Louis, MO, USA). They were then treated with $13 \mu \mathrm{M}$ BCB (SigmaAldrich, St. Louis, MO) diluted in DPBS at $38.5{ }^{\circ} \mathrm{C}, 5 \%$ $\mathrm{CO}_{2}$ for $90 \mathrm{~min}$. After treatment, the oocytes were transferred to DPBS and washed twice. During washing, the oocytes were examined under an inverted microscope and classified as stained blue $\left(\mathrm{BCB}^{+}\right)$or colorless $(\mathrm{BCB}$ $\left.{ }^{-}\right)$. Only the granulosa cell-free $\mathrm{BCB}^{+}$oocytes were used for subsequent molecular analysis (before IVM group) or IVM followed by second BCB test and molecular analysis (after IVM group).

\section{In vitro maturation of porcine $\mathrm{COCS}$}

After the first $\mathrm{BCB}$ test, the $\mathrm{BCB}^{+} \mathrm{COCs}$ were subjected to IVM. Immature oocytes have compact cumulus cell layers that required removal for further oocyte evaluation. Thus, COCs were first incubated with bovine testicular hyaluronidase (Sigma-Aldrich, St. Louis, MO, USA) for 2 min at $38^{\circ} \mathrm{C}$ to separate cumulus and granulosa cells. Cells were then removed by vortexing the $\mathrm{BCB}^{+}$oocytes in $1 \%$ sodium citrate buffer followed by mechanical displacement using a small-diameter glass micropipette (Nichiryo, Nishikata, Japan). The COCs were cultured in $\operatorname{Nunclon}^{\mathrm{Tm}} \Delta$ 4-well dishes (Thermo Fisher Scientific, Waltham, MA, USA) in $500 \mu \mathrm{l}$ standard porcine IVM culture medium: TCM-199 (tissue culture medium) with Earle's salts and $L$-glutamine (Gibco BRL Life Technologies, Grand Island, NY, USA), supplemented with $2.2 \mathrm{mg} / \mathrm{ml}$ sodium bicarbonate (Nacalai Tesque, Inc., Kyoto, Japan), $0.1 \mathrm{mg} / \mathrm{ml}$ sodium pyruvate (Sigma-Aldrich, St. Louis, MO, USA), $10 \mathrm{mg} / \mathrm{ml}$ BSA (Bovine Serum Albumin) (Sigma-Aldrich, St. Louis, MO, USA), $0.1 \mathrm{mg} / \mathrm{ml}$ cysteine (Sigma-Aldrich, St. Louis, MO, USA), $10 \%(\mathrm{v} / \mathrm{v})$ filtered porcine follicular fluid, and gonadotropin supplements at final concentrations of $2.5 \mathrm{IU} / \mathrm{ml}$ hCG (human Chorionic Gonadotropin) (Ayerst Laboratories, Inc., Philadelphia, PA, USA) and $2.5 \mathrm{IU} / \mathrm{ml}$ eCG (equine Chorionic Gonadotropin) (Intervet, Whitby, ON, Canada). Wells were covered with a mineral oil overlay and cultured for $44 \mathrm{~h}$ at $38{ }^{\circ} \mathrm{C}$ under $5 \% \mathrm{CO}_{2}$. After cultivation, the $\mathrm{BCB}$ staining test was performed, and $\mathrm{BCB}^{+}$oocytes were used for further experiments.

\section{RNA extraction from porcine oocytes}

Total RNA was extracted from samples using TRI Reagent (Sigma, St Louis, MO, USA) and RNeasy MinElute cleanup Kit (Qiagen, Hilden, Germany). The amount of total mRNA was determined from the optical density at $260 \mathrm{~nm}$, and the RNA purity was estimated using the 260/ $280 \mathrm{~nm}$ absorption ratio (higher than 1.8) (Nano Drop spectrophotometer, Thermo Scientific, ALAB, Poland). The RNA integrity and quality were checked on a Bioanalyzer 2100 (Agilent Technologies, Inc., Santa Clara, CA, USA). The resulting RNA integrity numbers (RINs) were between 8.5 and 10 with an average of 9.2 (Agilent Technologies, Inc., Santa Clara, CA, USA). The RNA in each sample was diluted to a concentration of $100 \mathrm{ng} / \mu \mathrm{l}$ with an OD260/ OD280 ratio of 1.8/2.0. From each RNA sample, $500 \mathrm{ng}$ of RNA was taken. The remaining amount of isolated RNA was used for the RT-qPCR study.

\section{Microarray expression analysis and statistics}

The Affymetrix procedure was previously described by Trejter et al. [21]. Total RNA (100 ng) from each pooled sample was subjected to two rounds of sense cDNA amplification (Ambion ${ }^{\circ}$ WT Expression Kit). The cDNA was used for biotin labeling and fragmentation by Affymetrix Gene Chip ${ }^{\circ}$ WT Terminal Labeling and Hybridization (Affymetrix). Biotin-labeled fragments of cDNA $(5.5 \mu \mathrm{g})$ were hybridized to Affymetrix ${ }^{\circ}$ Porcine Gene 1.1 ST Array Strip $\left(48{ }^{\circ} \mathrm{C} / 20 \mathrm{~h}\right)$, where the expression profile of 12,258 porcine transcripts was examined. Microarrays were then washed and stained according to the technical protocol using the Affymetrix Gene Atlas Fuidics Station. The array strips were scanned employing Imaging Station of the Gene Atlas System. Preliminary analysis of the scanned chips was performed using Affymetrix Gene Atlas TM Operating Software. The quality of the gene expression data was checked according to quality control criteria provided by the software. Obtained CEL files were imported into downstream data analysis software.

All analyses were performed using Bioconductor software based on the statistical $\mathrm{R}$ programming language. For background correction, normalization, and summation of raw data, the Robust Multiarray Averaging (RMA) algorithm implemented in "affy" package of Bioconductor was applied. Biological annotation was taken from Bioconductor "oligo" package where the annotated data frame object was merged with a normalized data set, leading to a complete gene data table. Statistical significance of the analyzed genes was performed by moderated $\mathrm{t}$-statistics from the empirical Bayes method. Obtained $p$-values were corrected for multiple comparisons using the Benjamini and Hochberg's false discovery rate. Selection of significantly changed gene expression values (differentially expressed genes) was based on a $p$-value below 0.05 and an expression fold higher than $|2|$. The homogeneity of analyzed groups was checked 
by a principal component analysis (PCA) algorithm incorporated in "rgl" Bioconductor package.

Differentially expressed genes were subjected to the selection of genes associated with BMP signaling pathways. Differentially expressed gene lists (separated for up- and down-regulated) were uploaded to DAVID software (Database for Annotation, Visualization and Integrated Discovery) where differentially expressed genes belonging to "BMP signaling pathway" gene ontology biological process group (GO BP) were obtained [22]. Expression data of these genes were subjected to a hierarchical clusterization procedure and presented as a heatmap.

Interactions between differentially expressed genes/ proteins belonging to "BMP signaling pathway" ontology group were investigated by STRING10 software (Search Tool for the Retrieval of Interacting Genes) [23]. List of gene names was used as query for interaction prediction. Search criteria were based on co-occurrences of genes/ proteins in scientific texts (text mining), co-expression, and experimentally observed interactions. The results of this analysis generated a gene/protein interaction network where the intensity of the edges reflects the strength of the interaction score. In addition to interaction prediction, STRING also performs functional enrichments of GO terms based on previously uploaded gene sets from "BMP signaling pathway" GO BP term.

\section{Real-time quantitative polymerase chain reaction (RT-qPCR) analysis}

RT-qPCR analysis was performed in order to validate microarray results, using both the same RNA samples used for PCR and microarray profiling experiments.

Total RNA was isolated from oocytes before or after IVM. The RNA samples were re-suspended in $20 \mu \mathrm{l}$ of RNase-free water and stored in liquid nitrogen. RNA samples were treated with DNase I and reversetranscribed (RT) into cDNA. RT-qPCR was conducted in a Light Cycler real-time PCR detection system (Roche Diagnostics $\mathrm{GmbH}$, Mannheim, Germany) using SYBR ${ }^{\circ}$ Green I as a detection dye, and target cDNA was quantified using the relative quantification method. The relative abundance of CHRDL1, FST, TGFBR3, SMAD4, and ID1transcripts in each sample was standardized to the internal standards. For amplification, $2 \mu \mathrm{l}$ of cDNA solution was added to $18 \mu \mathrm{l}$ of QuantiTect ${ }^{\circ} \mathrm{SYBR}^{\circ}$ Green PCR (Master Mix Qiagen GmbH, Hilden, Germany) and primers (Table 1). One RNA sample of each preparation was processed without the RT-reaction to provide a negative control for subsequent PCR.

\section{Results}

From whole sets of 12,258 analyzed transcripts, 379 genes were down-regulated whereas 40 were up-regulated in relation to the oocyte transcriptome before and after the in vitro maturation procedure. Principal Component Analysis (PCA) confirmed the homogeneity of the groups, since we obtained two separated clusters corresponding to tested experimental groups (before and after IVM).

DAVID software extracted five genes sets belonging to "BMP signaling pathway" gene ontology biological process term (GO BP). The set of genes consisting of CHRDL1, FST, TGFßR3, SMAD4, and ID1 was subjected to hierarchical clusterization procedure and presented as a heatmap. Arbitrary signal intensity acquired from microarray analysis was represented by green (higher expression) and red (lower expression) colors. Log2 signal intensity values for any single gene were resized to Row Z-Score scale (from -2 - the lowest expression to +2 - the highest expression for single gene) (Fig. 1). The set of differentially expressed genes belonging to "BMP signaling pathway" GO BP term category is presented in Table 2 where their symbols, names, fold changes, and corrected $p$-values are shown.

Our analyses of differentially expressed genes, belonging to the BMP signaling pathway GO, with a use of STRING database revealed only weak interactions between ID1, SMAD4, and FST genes. We applied prediction methods such as text mining, co-expression and experimentally observed interactions, and found only weak interaction of protein homology. Strength of the interaction was reflected by the intensity of the edges.

STRING-generated functional enrichment of GO terms showed the top five GO terms that also belong to "BMP signaling pathway" GO BP. These terms include those that are very similar to "BMP signaling pathway" such as: "response to BMP", "cellular response to BMP stimulus", "transmembrane receptor protein serine/ threonine kinase signaling pathway", and "regulation of transmembrane receptor protein serine/threonine kinase signaling pathway", with their GO ID (pathway ID), GO term description (pathway description), and number of the genes belonging to appropriate category (count in gene set) (Table 3).

The result from the RT-qPCR revealed increased expression of CHRDL1, FST, TGF $\beta$ R3, SMAD4, and ID1 in porcine oocytes before IVM as compared to analysis after IVM. The RT-qPCR assay confirmed the fold change and significance of microarray expression profiling. Figure 2 shows comparison of both techniques with their respective fold changes for each gene.

\section{Discussion}

Maturation capability is defined as the ability of female gametes to undergo nuclear and cytoplasmic maturation [24]. This occurs when oocytes achieve the MII stage and RNA accumulates, creating the template for further protein synthesis during early embryogenesis [25]. It has been clearly demonstrated in several species of mammals, 
Table 1 Oligonucleotide sequences of primers used for RT-qPCR analysis

\begin{tabular}{|c|c|c|c|c|}
\hline Transcript & Sequence (5'-3' direction) & Gene accession no. & Product size (bp) & Efficiency \\
\hline$\overline{\text { CHRDL1 }}$ & $\begin{array}{l}\text { AACAATGCCTGTGTATGAGT } \\
\text { TCTGGGCTTCTCCTTCAGT }\end{array}$ & XM_005673817.2 & 242 & $91 \%$ \\
\hline FST & $\begin{array}{l}\text { GAGCCCACCTCCTCAGGAC } \\
\text { TCTCAGGGCACAGCTCATCG }\end{array}$ & NM_001003662.1 & 238 & $94 \%$ \\
\hline TGF $\beta$ R3 & $\begin{array}{l}\text { TGATCCACCATGAAGTGCAGT } \\
\text { TGCCTTCCTGCGCTGTCTC }\end{array}$ & NM_214272.1 & 190 & $108 \%$ \\
\hline ID1 & $\begin{array}{l}\text { AGCTGAACTCGGAATCCCAA } \\
\text { TTCAGCGACACAAGATGCGAT }\end{array}$ & NM_001244700.1 & 147 & $107 \%$ \\
\hline SMAD4 & $\begin{array}{l}\text { CCAAGTGCATATATAAAGGTCT } \\
\text { AGCCTITCACAAAACTCATCC }\end{array}$ & XM_013985326 & 235 & $98 \%$ \\
\hline PBGD & $\begin{array}{l}\text { GAGAGTGCCCCTATGATGCT } \\
\text { ATGATGGCACTGAACTCCT }\end{array}$ & NM_001097412.1 & $214 \mathrm{bp}$ & $97 \%$ \\
\hline B-ACTIN & $\begin{array}{l}\text { GGGAGATCGTGCGGGACAT } \\
\text { CGTTGCCGATGGTGATGAC }\end{array}$ & DQ845171 & $141 \mathrm{bp}$ & $99 \%$ \\
\hline $18 \mathrm{~S}$ rRNA & $\begin{array}{l}\text { GTGAAACTGCGAATGGCTC } \\
\text { CCGTCGGCATGTATTAGCT }\end{array}$ & AB117609 & $105 \mathrm{bp}$ & $97 \%$ \\
\hline
\end{tabular}

including domestic pigs, that only after proper maturation, the oocytes are fully fertilizable [26]. It has been also suggested that the maturation period is crucial for normal zygote formation and embryonic growth in the preimplantation stage [27]. Although in vitro culture (IVC) systems are applied to mimic in vivo conditions, the proportion of fully mature and fertilizable oocytes after IVC in numerous mammalian species is still unsatisfactory [28]. Recently, several studies aimed to find new molecular markers of oocyte maturation ability in order to improve IVC models and increase the number of fully mature gametes [29-33]. Therefore, in this study we performed gene expression analysis in porcine oocytes before and after

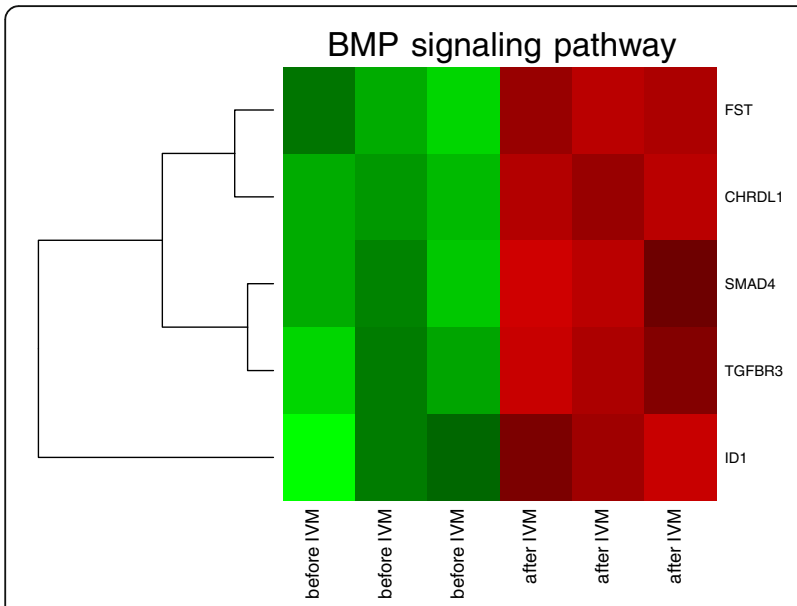

Fig. 1 Heat map representing differentially expressed genes belonging to the "BMP signaling pathway" - functional category from DAVID GEOTERM BP database. Arbitrary signal intensity acquired from microarray analysis is represented by colors (green - higher, red - lower expression). Log2 signal intensity values for any single gene were resized to Row Z-Score scale (from -2 - the lowest expression to +2 - the highest expression for single gene)
IVM in order to define new molecular markers of female gamete maturation capability. Using microarray analysis, we selected genes related to the BMP family that were significantly up-regulated before IVM as compared to after IVM.

Chordin-like 1 (CHRDL1), also known as ventroptin (VOPT), is a protein involved in retina and tectum development, is crucial for topographic retinotectal projection, and is a known BMP4 antagonist [34]. Recent findings by Webb et al. [35] showed the expression of ventroptin in the developing human cornea and neural retina as early as week 7 of gestation. Additionally, they observed ventroptin expression in fetal organs such as the cerebellum as well as the prefrontal and occipital neocortex. These data suggest that CHRDL1 may belong to proteins involved in morphogenesis and organogenesis in mammals. The results from our experiments indicated CHRDL1 was significantly up-regulated before IVM as compared to oocytes analyzed after IVM. Since CHRDL1 is a secreted protein expressed mostly in

Table 2 Fold changes and adjusted $p$-values of differentially expressed genes

\begin{tabular}{llll}
\hline Gene symbol & Gene name & Fold change & Adj. $p$ value \\
\hline CHRDL1 & chordin-like 1 & $-7,18$ & 0,00005 \\
TGFBR3 & $\begin{array}{l}\text { transforming growth } \\
\text { factor, beta receptor III }\end{array}$ & $-5,09$ & 0,00041 \\
FST & follistatin & $-4,45$ & 000036 \\
ID1 & $\begin{array}{l}\text { Inhibitor of DN binding 1, } \\
\text { dominant negative }\end{array}$ & $-2,98$ & 0,00397 \\
& helix-loop-helix protein & & \\
SMAD4 & SMAD family member 4 & $-2,72$ & 0,00124 \\
\hline
\end{tabular}

Fold changes and adjusted $p$-values of differentially expressed genes belonging to the "BMP signaling pathway" functional category from DAVID GEOTERM BP database. Symbols and names of the selected genes are also shown 
Table 3 Top five GO categories formed by differentially expressed genes

\begin{tabular}{lll}
\hline Biological Process (GO) \\
\hline Pathway ID & Pathway Description & Count in gene set \\
\hline GO: 0030509 & BMP signaling pathway & 4 \\
GO: 0071772 & Response to BMP & 4 \\
GO: 0071773 & $\begin{array}{l}\text { Cellular response to BMP } \\
\text { stimulus }\end{array}$ & 4 \\
GO: 0007178 & $\begin{array}{l}\text { Transmembrane receptor } \\
\text { protein serine/threonine } \\
\text { kinase signaling pathway }\end{array}$ & 4 \\
GO: 0090092 & $\begin{array}{l}\text { Regulation of transmembrane } \\
\text { receptor protein serine/threonine }\end{array}$ & 4 \\
& kinase signaling pathway & \\
\hline
\end{tabular}

Top five GO categories formed by differentially expressed genes belonging to the "BMP signaling pathway" ontology group. GO categories were generated in STRING software. GO ID (pathway ID), GO term description (pathway description) number of the genes belonging to appropriate category (count in gene set) are shown

mesenchymal tissue during morphogenesis and organogenesis [36], its expression may be possibly related to embryos as opposed to mature oocytes. Moreover, higher expression of CHRDL1 in porcine oocytes before IVM let us assume that BMP-related morphogenesis may be significantly associated with early folliculogenesis in immature oocytes. Bachiller et al. [37], found that CHRDL1 (-/-) mice died during embryogenesis or perinatelly, what let us assume that this morphogenesis-related gene expression is more likely associated with embryo growth and development than with achievement of maturation capability in porcine oocytes.

A significant role of the TGF signaling pathway during early morphogenesis and organogenesis has also been determined [38]. In this study, we observed that induction of the BMP signaling pathway can be also associated with up-regulated gene expression of TGF family member follistatin (FST) and genes related to TGF signaling, such as transforming growth factor-beta receptor-type III (TGF $\beta$ R3). Additionally, altered expression of the mother against decapentaplegic homolog 4 (SMAD4) transcript, known as the main mediator of TGF-beta (TGF $\beta$ ) and BMP1 signal transduction, was also observed.

Recently, Inman et al. [39] reported that TGF $\beta$ receptor (TGF $\beta R$ ) activity is required for nuclear SMAD activation, which regulates induction of TGF $\beta R$ transcription. This bi-directional transport of SMADs/ TGF $\beta R$ between the nucleus and cytoplasm provides the information regarding signaling pathways and events leading to the transcriptional activation of target genes. It has been suggested that activing- and activing receptor-related systems are involved in regulatory processes responsible for the maturational capability of oocytes [40].

The results of our microarray experiments clearly demonstrated up-regulation of all three members of TGF family: FST, TGF $\beta 3$, and SMAD4 in porcine oocytes before IVM compared to those analyzed after IVM. We therefore hypothesize that FST, TGF $\beta$ R3, and SMAD4 could be involved in oocyte maturational competence, as well as induction of the TGF/TGFR signaling pathway. The latter could significantly improve the oocyte-follicular cell bi-directional shuttling. Our results may indicate that expression and likely release of FST out of the oocyte improve follicular cell growth and differentiation. Similar to Wang and Ge [41], we observed

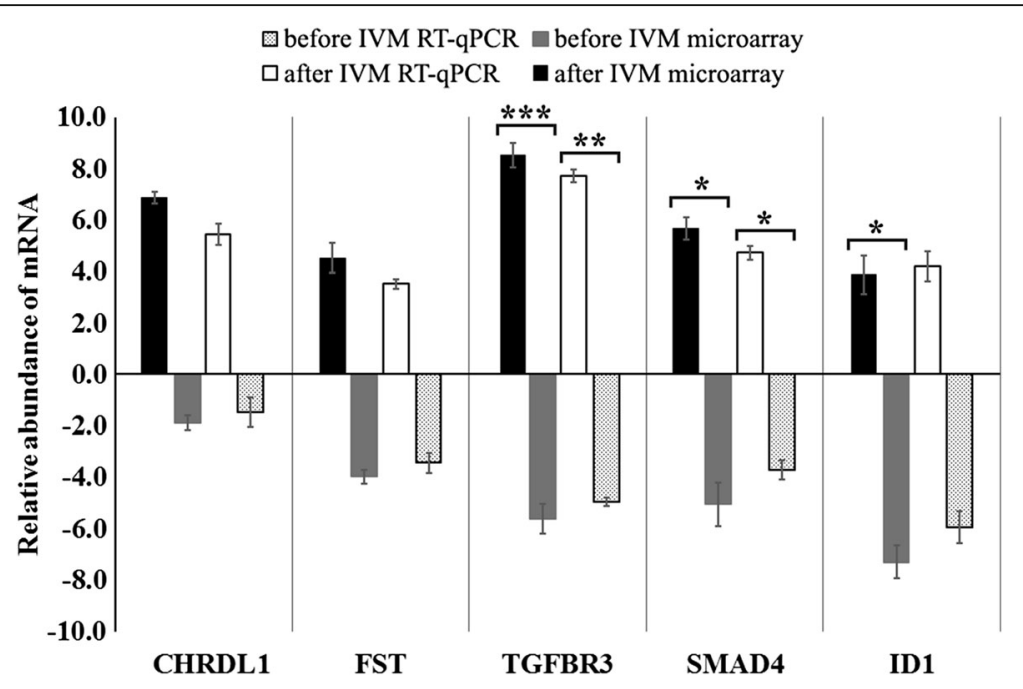

Fig. 2 Validation of microarray data by RT-qPCR. Comparison of gene expression analysis of oocytes before IVM and after IVM using microarray assay and RT-qPCR. RT-qPCR analysis was normalized to the expression of three housekeeping genes (PBGD, $\beta$-actin, $18 \mathrm{~S}$ rRNA). Error bars represent the standard error of the mean (SEM) for groups of oocytes. Statistically significant differences are presented as: ${ }^{*} p<0.05,{ }^{* *} p<0.01$, and ${ }^{* * *} p<0.001$ 
TGF $\beta$-related genes are up-regulated in oocytes before compared to after IVM gametes. Al-Edani et al., also observed up-regulated expression of TGF $\beta$ R3 gene in human cumulus cells, supposedly as the result of enhanced angiogenesis, playing essential role in late stages of folliculogenesis [42]. Furthermore, Rodriques et al., found TGF $\beta$, TGF $\beta$ R I and R II mRNA in oocytes of all follicle stages as well as in granulosa cells of primary and secondary follicles in caprine [43]. That is why, we cannot exclude the existence of a TGF/TGF $\beta / T G F \beta R$ signaling cascade between oocytes and follicular cells, which maintains significantly higher activity at early stages of oogenesis and folliculogenesis.

It is likely that activation of the TGF signaling pathway in both oocytes and follicular cells is necessary for proper growth, development, and maintenance of proper maturational capability of porcine oocytes [44]. Results obtained by Guéripel et al. can confirm this hypothesis, since they observed increased expression of TGF $\beta$ signaling pathway genes and proteins in mice exposed to FSH an LH treatment. Significant expression of TGF $\beta$ R I and R II in theca interna, whereas much lower expression in GCs was found. The Smads exhibited strong expression in oocytes, GCs, and luteal cells but lower expression in the theca interna. Among the Smads, Smad4 had the highest expression [45].

It was well defined that oocyte maturational competence is significantly regulated by bi-directional shuttling of oocytes and somatic cumulus cells [46]. The transport of molecules between these cells improves the metabolic status and significantly regulates the maturation ability of oocytes. Moreover, our recent studies clearly demonstrated that oocyte-cumulus cross-talk supports somatic cell proliferation and differentiation in vitro [47]. Although the important role of CCs surrounding oocytes in gametes maturational competence achievement is widely known [48], there is relatively little data indicating the molecular basis of this process. Indeed, Salhab et al. used microarray assays to identify a transcriptomic profile in bovine CCs. Among 472 differentially expressed transcripts in CCs, TGF $\beta$ signaling GO was up-regulated, whereas MAP kinases pathway GO was down-regulated. Additionally, the protein assays showed an increased abundance of Smad4 in CCs after oocyte's IVM. The phosphorylation status of SMAD2, MAPK3/1, and MAPK14, but not MAPK8, was higher in the cells after IVM as compared to immature complexes. They concluded that in vitro maturation leads to increased activity of the TGF $\beta$ and MAPK signaling pathways, simultaneous with decreased oocyte quality [49].

Contrary to these results, the current study observes significantly lower expression of TGF/TGF $\beta$ signaling related genes. Thus, we suspect an important role of this ontological group in the early stages of folliculogenesis and oogenesis, likely leading to maturational competence of oocytes in pigs. Although, the function of Smad4 as the mediator of early embryogenesis is not entirely known, the role of SMAD4 as a regulator of SMAD2/3- and SMAD1/5/8 signaling pathways activation and FST expression was recently documented in cattle oocytes by Lee et al. Contrary to our observations, they found that Smad4 mRNA was significantly higher during oocyte's IVM with a maximum at 2-cell stage embryos and 8-cell stage to the lower level at blastocyst, concluding SMAD4 may be recognized as the main factor required for normal embryogenesis in cattle at 8-cell, 16-cell, and blastocyst stage [50]. Taking into account also our observations, it is possible that SMAD4 is an important component of the TGF $\beta$ signaling pathway responsible for regulation of proper oogenesis and embryogenesis as well as achievement and maintenance of normal maturational status in both pigs and cattle.

It was well recognized in several species of mammals that the proper achievement of oocyte maturational capability is significantly orchestrated by cumulus cell proliferation and differentiation both in vivo and in vitro. Hogg et al. [51], examined ovine ovary, and found ID 1-4 expression in granulosa and theca cells in ovarian follicles during their development. Finally, they hypothesized that ID proteins may play a key role in steroidogenic cells' regulation of growth and differentiation. This observation together with ID1 known functions of proliferation maintenance and differentiation inhibition [14], may indicate that ID1 can be involved in transcriptional regulation essential for normal folliculogenesis. Although the role of ID1 as an important transcriptional activating factor in the mediation of cellular growth, development, proliferation, and differentiation is well known [14], there exists only one description regarding an ID1 expression profile and oocyte maturation. Similarly to us, Blaha et al. using microarray assay investigated the effect of FSH administration on gene expression patterns in porcine $\mathrm{cu}-$ mulus cells. They found that FSH administration led to increased expression of genes encoding transcription factors including ID1. Finally, they concluded that FSH-induced expression of genes is responsible for regulation of cumulus cell differentiation and the events leading to successful oocytes in vitro maturation [52].

\section{Conclusions}

Higher expression of CHRDL1, FST, TGF $\beta$ R3, SMAD4, and ID1 genes before IVM, as compared to oocytes analyzed after IVM, points these genes may be potential mediators of fully maturational competent gamete formation both in the nucleus and cytoplasm. We hypothesize that BMP signaling pathway genes influence regulatory processes at early stages of porcine oogenesis, however significance of this finding needs further investigation with a use of protein assays. 


\section{Abbreviations}

ALK: Activing-related kinases; BMP: Bone morphogenetic protein; CCs: Cumulus cells; CHRDL1: Chordin-like 1; COCs: Cumulus-oocyte complexes; DAVID: Database for annotation, visualization and integrated discovery; FST: Follistatin; GCs: Granulosa cells; GJCs: Gap junction connections; GO BP: Gene ontology biological process group; HLH: Helix-loop-helix (architecture); ID1: Inhibitor of DNA binding 1; IVM: In vitro maturation; PCA: Principal component analysis; RMA: Robust Multiarray averaging; SMAD: Decapentaplegic homolog; STRING: Search tool for the retrieval of interacting genes; TGF $\beta$ : Transforming Growth Factor beta; TGF $\beta R$ : Transforming Growth Factor Beta Receptor; VOPT: Ventroptin

\section{Acknowledgements}

The authors thank Rotem Kahan for linguistic help in manuscript preparation.

\section{Funding}

The study was supported by grant number 2014/13/D/NZ9/04798 "SONATA" and UMO-2011/03/N/NZ4/00305 from the Polish National Science Centre.

\section{Availability of data and materials}

Please contact author for data requests.

\section{Authors' contributions}

$\mathrm{JB}$ - performed the experiment, author of the concept of the article, the author responsible for the manuscript. MR- collection of the biological material. SC-performed the experiment, $\mathrm{BCB}$ tests and IVM. AB- microarray expression and statistical analysis. SB-collection of the biological material. WK- performed the real-time quantitative polymerase chain reaction analysis. KWM- collection of the biological material. MJ- molecular assays, preparation of the tables and figs. ES- preparation of the literature for the manuscript. DB- animals healthcare evaluation. PA- animals healthcare evaluation. KPBeditorial assistance. MB- editorial assistance, verification and acceptance of the manuscript. MN- supervision of manuscript writing, verification and approval of the manuscript, provision of technical advice. MZ- supervision of manuscript writing. BK- senior author and major assistance. All authors read and approved the final manuscript.

\section{Competing interests}

The authors declare they have no competing interests.

\section{Consent for publication}

Not applicable.

\section{Ethics approval and consent to participate}

This study has been approved with resolution 32/2012 by Bioethical Committee at the Poznan University of Medical Sciences.

\section{Author details}

'Department of Histology and Embryology, Poznan University of Medical Sciences, Swiecickiego 6 St., 60-781 Poznan, Poland. ${ }^{2}$ Institute of Veterinary Sciences, Poznan University of Life Sciences, Wolynska 35 St, 60-637 Poznan, Poland. ${ }^{3}$ Department of Anatomy, Poznan University of Medical Sciences, Swiecickiego 6 St, 60-781 Poznan, Poland. ${ }^{4}$ Department of Obstetrics and Gynecology, University Hospital and Masaryk University, Obilnitrh 11, 60200 Brno, Czech Republic.

\section{Received: 25 February 2017 Accepted: 26 May 2017}

\section{Published online: 02 June 2017}

\section{References}

1. Yokoo M, Sato E. Cumulus-oocyte complex interactions during oocyte maturation. Int rev Cytol. 2004;235:251-91.

2. Kidder GM, Vanderhyden BC. Bidirectional communication between oocytes and follicle cells: ensuring oocyte developmental competence. Can J Physiol Pharmacol. 2010;88:399-413.

3. Kempisty B, Ziolkowska A, Ciesiolka S, Piotrowska H, Antosik P, Bukowska D, et al. Study on connexin gene and protein expression and cellular distribution in relation to real-time proliferation of porcine granulosa cells. J Biol Regul Homeost Agents. 2014;28:625-35.

4. Uyar A, Torrealday S, Seli E. Cumulus and granulosa cell markers of oocyte and embryo quality. Fertil Steril. 2013;99:979-97.
5. Kempisty B, Piotrowska H, Walczak R, Śniadek P, Dziuban J, Bukowska D, et al. Factors with an influence on mammalian oocytes developmental potential in light of molecular and microfluidic research. Medycyna wet. 2011;67:435-9.

6. Lei $X$, Cui $K$, Cai X, Ren Y, Liu Q, Shi D. Bone morphogenetic protein 1 is expressed in porcine ovarian follicles and promotes oocyte maturation and early embryonic development. J vet med Sci. 2017;79:258-66.

7. Zhu G, Guo B, Pan D, Mu Y, Feng S. Expression of bone morphogenetic proteins and receptors in porcine cumulus-oocyte complexes during in vitro maturation. Anim Reprod Sci. 2008;104:275-83.

8. Piotrowska H, Kempisty B, Sosinska P, Ciesiolka S, Bukowska D, Antosik P, et al. The role of TGF superfamily gene expression in the regulation of folliculogenesis and oogenesis in mammals: a review. Vet med-Czech. 2013; 58:505-15.

9. Korchynskyi $\mathrm{O}$, ten Dijke P. Identification and functional characterization of distinct critically important bone morphogenetic protein-specific response elements in the Id1 promoter. J Biol Chem. 2002;277:4883-91.

10. Massaque J. TGF-beta signal transduction. Annu rev Biochem. 1998;67:753-91.

11. Liu KJ, Harland RM. Cloning and characterization of Xenopus Id4 reveals differing roles for id genes. Dev Biol. 2003;264:339-51.

12. Peng $Y$, Kang Q, Luo Q, Jiang W, Si W, Liu BA, et al. Inhibitor of DNA binding/ differentiation helix-loop-helix proteins mediate bone morphogenetic proteininduced Osteoblast differentiation of Mesenchymal stem cells. J Biol Chem. 2004;279:32941-9.

13. Yu Y, Liang Y, Yin C, Liu X, Su Y, Zhang L, et al. Inhibitor of DNA-binding 1 promotes endothelial progenitor cell proliferation and migration by suppressing E2-2 through the helix-loop-helix domain. Int J Mol med. 2016;38:1549-57.

14. Ling F, Kang B, Sun XH. Id proteins: small molecules, mighty regulators. Curr top dev Biol. 2014;110:189-216.

15. Leddy HA, McNulty AL, Lee SH, Rothfusz NE, Gloss B, Kirby ML, et al. Follistatin in chondrocytes: the link between TRPV4 channelopathies and skeletal malformations. FASEB j. 2014;28:2525-37.

16. Taylor SE, Lee J, Smeriglio P, Razzaque A, Smith RL, Dragoo JL. Identification of human juvenile chondrocyte-specific factors that stimulate stemm cell growth. Tissue eng Part a. 2016;22:645-53.

17. Balemans W, Van Hul W. Extracellular regulation of BMP signaling in vertebrates: a cocktail of modulators. Dev Biol 2002;250:231-50.

18. Shimasaki S, Zachow RJ, Li D, Kim H, lemura S-I, Ueno N, et al. A functional bone morphogenetic protein system in the ovary. Proc Natl Acad Sci U S a. 1999:96:7282-7.

19. Miyoshi T, Otsuka F, Inagaki K, Otani H, Takeda M, Suzuki J, et al. Differential regulation of Steroidogenesis by bone morphogenetic proteins in Granulosa cells: involvement of Extracellularly regulated Kinase signaling and Oocyte actions in follicle stimulating hormone-induced estrogen production. Endocrinology. 2007;148:337-45

20. Ericsson SA, Boice ML, Funahashi H, Day BN. Assessment of porcine oocytes using brilliant cresyl blue. Theriogenology. 1993;39:214.

21. Trejter M, Hochol A, Tyczewska M, Ziolkowska A, Jopek K, Szyszka M, et al. Sex-related gene expression profiles in the adrenal cortex in the mature rat: microarray analysis with emphasis on genes involved in steroidogenesis. Int J Mol med. 2015;35:702-14.

22. Huang DW, Sherman BT, Tan Q, Kir J, Liu D, Bryant D, et al. DAVID bioinformatics resources: expanded annotation database and novel algorithms to better extract biology from large gene lists. Nucleic Acids res. 2007;35:W169-75.

23. von Mering $C$, Jensen $L J$, Snel B, Hooper SD, Krupp M, Foglierini M, et al. STRING: known and predicted protein-protein associations, integrated and transferred across organisms. Nucleic Acids res. 2005;33:D433-7.

24. Eppig JJ. Coordination of nuclear and cytoplasmic oocyte maturation in eutherian mammals. Reprod Fertil dev. 1996;8:485-9.

25. Dunning KR, Lane M, Brown HM, Yeo C, Robker RL, Russell DL. Altered composition of the cumulus-oocyte complex matrix during in vitro maturation of oocytes. Hum Reprod. 2007;22:2842-50.

26. Kempisty B, Jackowska M, Bukowska D, Antosik P, Woźna M, Jaśkowski JM Mechanisms regulating oogenesis, folliculogenesis and fertilization in pigs. Medycyna wet. 2011;67:299-303.

27. Marques MG, Nicacio AC, de Oliveira VP, Nascimento AB, Caetano HV, Mendes $C M$, et al. In vitro maturation of pig oocytes with different media, hormone and meiosis inhibitors. Anim Reprod Sci. 2007;97(3-4):375-381.

28. Nogueira D, Sadeu JC, Montagut J. In vitro oocyte maturation: current status. Semin Reprod med. 2012;30:199-213. 
29. Yerushalmi GM, Maman E, Yung Y, Kedem A, Hourvitz A. Molecular characterization of the human ovulatory cascade-lesson from the IVF/IVM model. J Assist Reprod Genet. 2011;28:509-15.

30. Huang X, Hao C, Shen X, Zhang Y, Liu X. RUNX, GPX3 and PTX3 gene expression profiling in cumulus cells are reflective oocyte/embryo competence and potentially reliable predictors of embryo developmental competence in PCOS patients. Reprod Biol Endocrinol. 2013;11:109.

31. Arias-Alvarez M, Garcia-Garcia RM. Lopez-Tello J. Rebollar PG: Gutierezz-Adan A, Lorenzo PL. In vivo and in vitro maturation of rabbit oocytes differently affects the gene expression profile, mitochondrial distribution, apoptosis and early embryo development. Reproduction, fertility, and development; 2016. Epub ahead of print

32. Dieci C, Lodde V, Labreque R, Dufort I, Tessaro I, Sirard MA. At al. Differences in cumulus cell gene expression indicate the benefit of a pre-maturation step to improve in-vitro bovine embryo production. Mol hum Reprod. 2016; 22:882-97.

33. Kranc W, Budna J, Chachuła A, Borys S, Bryja A, Rybska M, et al. "cell migration" is the ontology group differentially expressed in porcine oocytes before and after in vitro maturation: a microarray approach. DNA Cell Biol. 2017;36:273-82.

34. Sakuta H, Suzuki R, Takahashi H, Kato A, Shintani T, lemura S, et al. Ventroptin: a BMP-4 antagonist expressed in a double-gradient pattern in the retina. Science. 2001;293:111-5.

35. Webb TR, Matarin M, Gardner JC, Kelberman D, Hassan H, Ang W, et al. Xlinked megalocornea caused by mutations in CHRDL1 identifies an essential role for ventroptin in anterior segment development. Am J hum Genet. 2012;90:247-59.

36. Allen JM, McGlinn E, Hill A, Warman ML. Autopodial develoment is selectively impaired by misexpression of chordin-like 1 in the chick limb. Dev Biol. 2013; 381:159-69.

37. Bachiller D, Klingensmith J, Shneyder N, Tran U, Anderson R, Rossant J. The role of chordin/bmp signals in mammalian pharyngeal development and DiGeorge syndrome. Development. 2003;130:3567-78.

38. Mullen AC, Wrana JL. TGF- $\beta$ signaling in embryonic and somatic stem-cell renewal and differentiation. Cold Spring Harb Perspect Biol. 2017; Epub ahead of print

39. Inman GJ, Nicolas FJ, Hill CS. Nucleocytoplasmic shuttling of Smads 2, 3, and 4 permits sensing of TGF-beta receptor activity. Mol Cell. 2002;10:283-94.

40. Yu C, Zhou JJ, Fan HY. Studying functions of TGF- $\beta$ signaling in the ovary. Methods Mol Biol. 2016;1344:301-11.

41. Wang Y, Ge W. Spatial expression patterns of activin and its signaling system in the zebrafish ovarian follicle: evidence for paracrine action of activin on the oocytes. Biol Reprod. 2003;69:1998-2006.

42. Al-Edani T, Assou S, Ferrieres A, Bringer Deutsch S, Gala A, Lecellier CH, et al. Female aging alters expression of human cumulus cells genes that are essential for oocyte quality. Biomed res Int. 2014;2014:964614.

43. Rodrigues GQ, Bertoldo MJ, Brito IR, Silva CM, Sales AD, Castro SV, et al. Relative mRNA expression and immunolocalization for transforming growth factor-beta (TGF- $\beta$ ) and their effect on in vitro development of caprine preantral follicles. In vitro cellular \& developmental biology. Animal. 2014;50: 688-99

44. Knight PG, Glister C. Local roles of GF-beta superfamily members in the control of ovarian follicle development. Aimal Reproduction Science. 2003; 78:165-83.

45. Gueripel X, Benahmed M, Gougeon A. Sequential gonadotropin treatment of immature mice leads to amplification of transforming growth factor beta action, via upregulation of receptor-type 1, Smad 2 and 4, and downregulation of Smad 6. Biol Reprod. 2004;70:640-8.

46. Chang HM, Qiao J, Leung PC. Oocyte-somatic cell interactions in the human ovary - novel role of bone morphogenetic proteins and growth differentation factors. Hum Reprod Update. 2016;23:1-18.

47. Kempisty B, Ziółkowska A, Piotrowska H, Zawierucha P, Antosik P, Bukowska $D$, et al. Real-time proliferation of porcine cumulus cells is related to the protein levels and cellular distribution of Cdk4 and Cx43. Theriogenology. 2013:80:411-20

48. Appeltant R, Somfai T, Nakai M, Bodo S, Maes D, Kikuchi K, et al. Interactions between oocytes and cumulus cells during in vitro maturation of porcine cumulus - oocyte complexes in a chemically defined medium: effect of denuded oocytes on cumulus expansion and oocyte maturation. Theriogenology. 2015;83:567-76.
49. Salhab M, Dhorne-Pollet S, Auclair S, Guyader-Joly C, Brisard D, Dalbies-Tran R, et al. In vitro maturation of oocytes alters gene expression and signaling pathways in bovine cumulus cells. Mol Reprod dev. 2013;80:166-82.

50. Lee KB, Zhang K, Folger JK, Knott JG, Smith GW. Evidence supporting a functional requirement of SMAD4 for bovine preimplantation embryonic development: a potential link to embryotrophic actions of follistatin. Biol Reprod. 2014;91:62.

51. Hogg K, Etherington SL, Young JM, MCNeilly AS, Duncan WC. Inhibitor of differentiation (id) genes are expressed in the steroidogenic cells of the ovine ovary and are differentially regulated by members of the transforming growth factor-beta family. Endocrinology. 2010;151:1247-56.

52. Blaha M, Nemcova L, Kepkova KV, Vodicka P, Prochazka R. Gene expression analysis of pig cumulus-oocyte complexes stimulated in vitro with follicle stimulating hormone or epidermal growth factor-like peptides. Reprod Biol Endocrinol. 2015:13:113.

\section{Submit your next manuscript to BioMed Central and we will help you at every step:}

- We accept pre-submission inquiries

- Our selector tool helps you to find the most relevant journal

- We provide round the clock customer support

- Convenient online submission

- Thorough peer review

- Inclusion in PubMed and all major indexing services

- Maximum visibility for your research

Submit your manuscript at www.biomedcentral.com/submit
C Biomed Central 